\title{
Measuring the Influence of Nutritional Messages Using Biomedical Data Package 2T Statistical Program
}

Syed A. Hussain, Ph.D.

Oak Brook, Illinois

DOI: http://dx.doi.org/10.5915/19-3-13016

\begin{abstract}
This research measures the effects that an American Heart Association nutritional game "Food for Thought" had upon the mean intake of calories, desserts, and skim milk of patrons of a university cafeteria. Patron food choices were unobtrusively measured for 16 weeks by means of a computerized cash register inventory system before, during, and after introduction of a media based nutritional game. The effects of this nutritional game on the dietary behavior of the patrons were estimated using BMDP2T Statistical Program. During promotion of the game, patrons reduced their mean caloric intake by $5 \%$, desserts by $19 \%$, and increased their consumption of skim milk by $40 \%$. First order and compound intervention effects persisted after the game. As shown, the game was effective and yielded results generalizable to similar social marketing campaigns and educational programs.
\end{abstract}

Key Words: Caloric intake, nutritional game, first order, compount intrvention, Biomedical Data Package 2T, dietary behavior

America's number one dietary problem is excessive caloric intake. The purpose of the "Food For Thought"' game is to teach consumers how to reduce caloric intake and improve the nutritional quality of the calories consumed. It was developed at the $\mathrm{Na}$ tional Heart, Lung and Blood Institute ${ }^{x}$ as a mediabased, nutritional intervention program designed to influence food choices in cafeteria settings. The game imparts specific nutritional information about food normally served at lunch in cafeteria through the use of playing cards. The deck consists of an enlarged (3" $\times 5$ "), 52-card deck with jokers. Each card contains a different colorful and humorous nutritional message designed to educate the viewer in "proper" nutritional habits.

The "Food For Thought" game was chosen as the medium in this research because it presents nutritional messages in an authoritative, persuasive, and entertaining manner at the point of consumption and

From the University of Missouri, School of Education

Current Address: Swift-Eckrich, Inc., Research and Development, Oak Brook, IL

Presented at the 19th Annual IMA Convention, Washington, DC, 1986

Reprint Requests: Syed A. Hussain, Ph.D., SwiftEckrich, Inc., Research and Development, 1919 Swift Drive, Oak Brook, IL 60522 thus appears to be very effective. While the application of this game has been reported ${ }^{2}$, past research did not model the effects of the game using intervention time series procedures. Time series procedures provide information about the form (i.e., gradual vs. abrupt), duration (permanent vs. temporary), and intensity (impact profile) of the change in eating habits. Material and methods

The University of Missouri-Kansas City (UMKC) cafeteria was the location for this study. ${ }^{3}$ Approximately 1200 customers a day eat lunch at the cafeteria Monday through Friday. Results of interviews of 500 patrons conducted over a five-day period confirmed that a relatively stable population purchased an average of 3.7 lunches per week. The menu of the cafeteria features a variety of meals including main dishes, salads, desserts, and a delicatessen bar. Entree menus are repeated every 21 weekdays. The cafeteria was equipped with an inventory control cash register which recorded each food item purchased.

The average daily caloric values of meals, the percentage of desserts and skim milk were measured unobtrusively for 30 days (i.e. 6, 5-day work weeks) to establish the pre-intervention processes. (More weeks would have been valuable in the study, but unfortunately changes in students and menus on a semester schedule precluded this.) Patrons could select from approximately ninety food items each day. The dependent time series here are: (1) the average daily caloric intake (i.e., total 
calories/number of customers that day), (2) the daily percentage purchases of desserts, and (3) the daily percentage purchases of skim milks.

\section{The game}

During the four weeks of intervention (20 days), February 28 through April 1, 1983, "Food For Thought" cards were distributed by cashiers every weekday. To encourage patrons to participate and save cards, incentives were offered. A player's objective was to collect specific combinations of cards to receive a prize of nominal value. By doing so it was hoped that the consumer would read the messages on the cards.

During intervention, prizes were awarded at the end of each of the four weeks. In all, 428 decks of cards were given out and 10 point of purchase posters were displayed during the intervention. In addition, a research assistant was present at the cafeteria to answer questions about the game during lunch hours. The same parameters were evaluated for the following six weeks ( 30 days), the post-intervention period to evaluate the residual effects.

\section{Intervention analyses}

Intervention Analysis, as described by Box and $\mathrm{Tiao}^{4}, \mathrm{Glass}^{5}$, was used to model the impact of the game upon the dependent variables. Technical details for this section can be found in Box and Jenkins ${ }^{6}$, the primary reference for $2 t$. Notational conventions used in Box and Jenkins were followed. For example, " $\mathrm{B}$ " is used as the backshift operator. This expression does not mean "B multiples $\mathrm{Y}_{\mathrm{t}}$ ", but rather means that " $\mathrm{B}$ operates on $\mathrm{Y}_{\mathrm{t}}$ to shift it backward one point in time." B is thus similar to natural logarithm operator in Algebra, i.e., $B Y(t)=Y(t-1)$, and $\mathrm{B}^{\mathrm{d}} \mathrm{Y}(\mathrm{t})=\mathrm{Y}(\mathrm{t}-\mathrm{b})$ and the notation $\mathrm{s}, \mathrm{U}$, etc. denote parameters of caloric intake model. The general model is

$y(t)=\frac{(U(O)+U(1) B+U(2) B * * 2+\ldots+U(s) B * * s)}{(1-S(1) B-S(2) B * * 2-\ldots-S(r) B * * r)} \times(t-b)+N(t)$

Where $y(t)$ and $x(t)$ represent either deviations of $Y(t)$ and $X(t)$ from their means for stationary series or appropriately differenced series for initially nonstationary series $\mathrm{Y}(\mathrm{t})$ and $\mathrm{X}(\mathrm{t})$. The notation of Biomedical Data Package (BMDP) ${ }^{\gamma}$ is used here to facilitate presentation. ${ }^{* *}$ Denotes the process of exponentiation and $N(t)$ is an appropriate Autoregressive-Integrated Moving Average (ARIMA) noise model of form.

$$
N(1)=\quad \frac{(1-\Theta(1) B-\Theta(2) B * * 2 \ldots-\Theta(q) B * * q)}{(1-\phi(1) B-\phi(2) B * * 2 \ldots-\phi(q) B * * p)} a(t)
$$

For intervention modeling, the input series $\mathrm{X}(\mathrm{t})$ is a dichotomous variable representing the known occurence of an event (in this study, the "Food For Thought" Game). The output series $Y(t)$ is the dependent time series, either caloric intake $\mathrm{Yc}(\mathrm{t})$, percentage of desserts $\mathrm{Yd}(\mathrm{t})$, or the percentage of

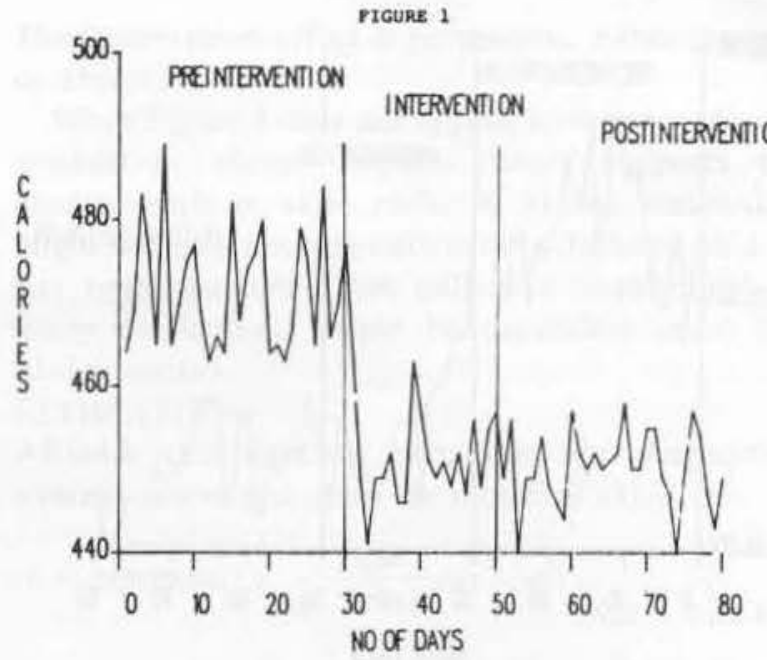

Figure 1: Average daily caloric value of purchases per customer in the UMKC cafeteria for 80 days. Intervention period 20 days, i.e. (4) 5-day work weeks, during which the "Food for Thought" game was played.

skim milk consumed $\mathrm{Ym}(\mathrm{t})$. These time series are given in Figures 1, 2, and 3. As shown there, the game was played from day 31 to day 50 . Biomedical Data Package 2T (BMDP2T) programs were used to identify, estimate, and diagnose the series.

For further explanation of these symbols and conventions see Appendix.

\section{Results}

\section{Caloric intake identification}

Figure 1 illustrates the pre-intervention, intervention and post-intervention time series of caloric intake. It appears stationary in the homogenous sense, yet, there is a hint of variance nonstationarity. The pre- and post-intervention series illustrates an effect which appears to be permanent after the game (i.e., after day 50 ).

The series has experienced an abrupt or gradual shift in caloric intake. The series of this study are short because the length of the semester controls the number of weeks the cafeteria patrons remain on campus. Theory would support a gradual shift in caloric intake as more and more patrons are exposed to the game through more posters and cards. Seasonality might exist because of the 21 day repeating menu. There is some hint of seasonality in the series which must be investigated further using ARIMA building procedures of Box-Jenkins. Several alternative intervention components are suggested, including abrupt or gradual, permanent or temporary, as well as compound effects that model the maintenance effects.

\section{ESTIMATION}

Using the alternative hypothesis procedure suggested 


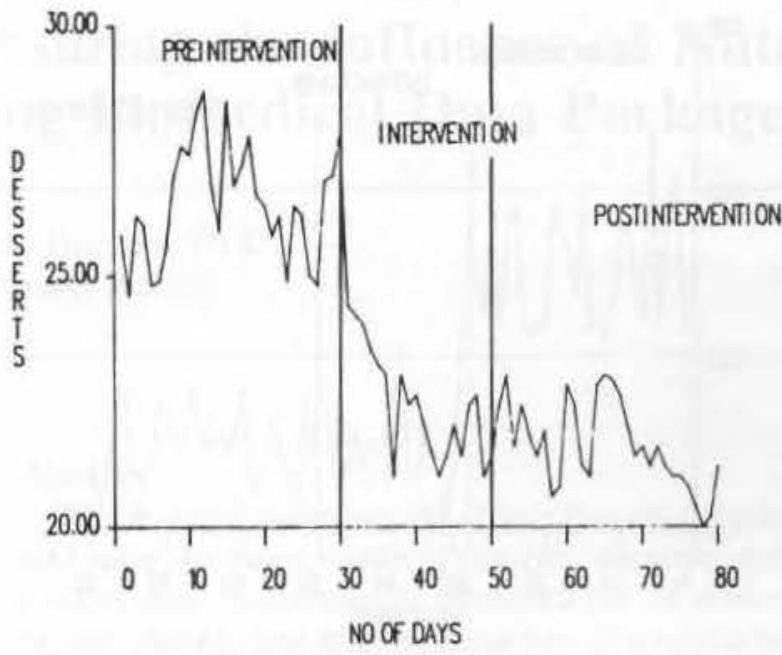

Figure 2: Daily percentage of selection (items purchased) in the dessert and sweet bread categories in the UMKC cafeteria for 80 days. Intervention period 20 days, i.e. (4) 5-day work weeks, during which the "Food for Thought" game was played.

by McCleary and Hay", the iterative procedures of identification, estimation and diagnostics converged upon a gradual, permanent model.

$$
\begin{aligned}
y c(t)=\frac{-11.72}{(1-.419 B)} \times(t)+\left(1-\begin{array}{l}
.8065 B * * 21) a(t)) \\
X(t)=0, t<31
\end{array}\right. \\
\qquad X(t)=1, t>30 \\
\text { Where } \bar{Y}_{c}=471.4 \quad \text { with t-statistic }=427.96 \\
\Theta c(21)=-.8065 \quad \text { with t-statistic }=-20.22 \\
\operatorname{Sc}(1)=.4160 \quad \text { with t-statistic }=3.06 \\
U_{c}(O)=-11.72 \quad \text { with t-statistic }=4.35
\end{aligned}
$$

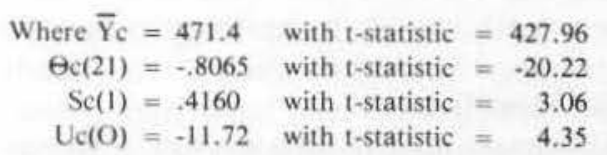

and the notation Sc, Uc, etc. denote parameters of the caloric intake model ( $\mathrm{d}$ and $\mathrm{m}$ are used to denote dessert and milk models, respectively).

\section{DIAGNOSTICS}

All parameter estimates are statistically significant at a .05 level with 75 degrees of freedom. Plots of residuals, autocorrelations, and partial correlations of the residuals confirm statistical adequacy. The Ljung-Box Q statistics was insignificant for short and long lags equaling 11.74 at 24 degrees of freedom (chi-sq. (table) $=36.415$, alpha $=.05,24 \mathrm{df}$ ).

The model is parsimonious and very importantly, it has substantive and theoretical appeal. More complex, compound intervention models confirmed the maintenance effect and yielded equivalent residual standard errors. The R-square for the model is

R-square(c) $=1 \quad \frac{\operatorname{MSE}(1)}{\operatorname{VAR}(\mathrm{Yc}(\mathrm{t}))}=1-\frac{22.8}{145.6}=84.5 \%$

\section{INTERPRETATION.}

During the pre-intervention period, the mean caloric intake remained relatively constant at 471.4 calories.
The impact of the game was gradual and permanent with an asymptotic change of -20.17 calories. The model implies an impact amounting to a drop of 20 calories (absolute).

Asymptotic change(c) $=\frac{U_{c}(O)}{1-S(1)}=\frac{-11.72}{1-.4190}=-20.17$

The gradual impact is rapid, the first day yields a 11.72 calorie decline, the third day, $93 \%$ of the asymptotic value, and by the 20th (last) day of intervention, the series has achieved almost $100 \%$ of the asymptotic value. Compound intervention modeling confirmed that the impact was permanent until the end of the semester. Because the student body left for the summer, it was not possible to determine how long the maintenance effect persisted.

\section{Desserts identification.}

Figure 2 illustrates the complete time series of desserts. The series does not appear stationary in the homogenous sense (i.e., with respect to level) and there may be a hint of variance nonstationarity. While it appears nonstationary, we must be cautious not to infer that the intervention effect is the normal process behavior. The pre- and post-intervention differences are pronounced and the intervention effect appears to be gradual and permanent event after the end of the game (i.e. period 50). Even though desserts are not on a 21 day cycle, there is some hint of seasonality in the series.

Theory supports the gradual shift in desserts illustrated in Figure 2. The "Food For Thought" game stressed not only low caloric intake, but better choices in the form of calories; desserts that possess high calories were discouraged on the game cards.

The decline in desserts was rather pronounced during the last two weeks of the semester. Unfortunately, it cannot be determined here why desserts had a rapid decline during periods $70-80$ days. The Spring semester was ending during this period and students were anticipating finals and, therefore, possibly modifying their eating habits. The intervention component suggested by Figure 2 is a gradual, permanent intervention.

\section{ESTIMATION}

The iterative procedures of identification, estimation and diagnostics strategy converged on (2).

$$
\begin{array}{ll}
y d(1)=\frac{-1.116}{(1-.7743 B)} x(t)+\quad & (1-.4875 B) a(t)) \\
& X(t)=0, t<31 \\
& X(t)=1, t>30
\end{array}
$$

$$
\begin{aligned}
\text { Where } \bar{Y} \mathrm{~d} & =26.56 \quad \text { with } t \text {-statistic }=120.36 \\
\Theta(1) & =-.4875 \text { with } t \text {-statistic }=-4.93 \\
S d(1) & =.7743 \text { with } t \text {-statistic }=14.64 \\
U d(O) & =-1.116 \text { with t-statistic }=-4.35
\end{aligned}
$$

DIAGNOSTICS.

All parameter estimates are statistically significant at 


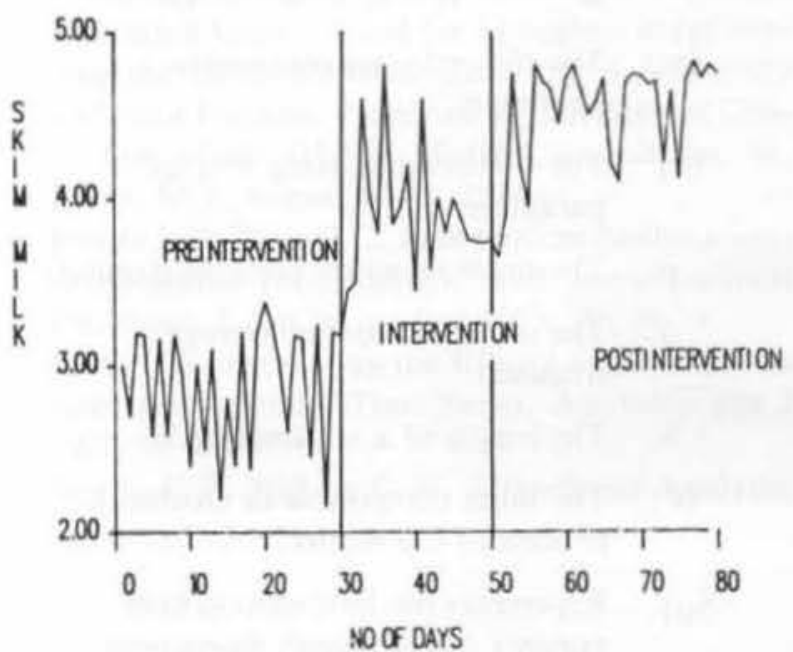

Figure 3: Daily percentage of selection (items purchased) in the $2 \%$ milk and skim milk categories in the UMKC cafeteria for 80 days. Intervention period 20 days, i.e. (4) 5-day work weeks, during which the "Food for Thought" game was played.

a .05 level with 75 degrees of freedom. The residual plots, autocorrelations, and partial autocorrelations of the residuals of the model confirm statistical adequacy, no significant peaks occur in the residual auto or partials of the model. The Ljung-box Q statistics was insignificant for short and long lags equaling 11.19 at 24 degrees of freedom (Chi-Square(table) = 36.415 for alpha $=.05$ for $24 \mathrm{df}$ ). This model is parsimonious and has substantive appeal and a good theoretical foundation. The R-square is

$R$-square(d) $=1-\frac{\operatorname{MSE}(2)}{\operatorname{VAR}(Y d(t))}=1-\frac{.662}{6.223}=89.4 \%$

INTERPRETATION.

During the pre-intervention period, the mean dessert rate was $26.56 \%$. Model (2) denotes that the impact of the game was gradual and permanent with an asymptotic change of $-4.94 \%$.

Asymptotic change $=\frac{\mathrm{Ud}(\mathrm{O})}{1-\mathrm{S}(1)}=\frac{-1.116}{1-.7743}=-4.94 \%$

On the first day of intervention, the percentage of desserts declined by $1.116 \%$, on the second day by $.86 \%$, and on the third day the decline was $.67 \%$ for a total decline of $2.646 \%$ in three days ( $54 \%$ of the asymptotic value). The impact is a gradual and permanent effect, persisting until the end of the semester. Again, compound intervention modeling confirmed that the impact was permanent until the end of the semester.

\section{Skim milk identification.}

Figure 3 illustrates the complete time series of skim milk. It appears stationary in level with significant differences in the pre-and post-intervention means.
The intervention effect is permanent, either gradual or abrupt.

While Figure 3 does not appear to support either a gradual or abrupt impact, theory supports the gradual shift in skim milk. A 21-day seasonality might not exist because milk is not scheduled on a 21 day repeating menu, yet milk is a complement to many meals (i.e., might be dependent upon the 21-day menu).

\section{ESTIMATION}

ARIMA identification, estimation and diagnostics strategy converged upon the model of (3).

$$
\begin{array}{ll}
(t+.2436 \mathrm{~B}) \mathrm{ym}(\mathrm{t})=\frac{.7508}{(1-.4071 \mathrm{~B})} \mathrm{x}(\mathrm{t})+\mathrm{a}(\mathrm{t}) & \\
\mathrm{X}(\mathrm{t})=0, t<31 \\
\mathrm{X}(\mathrm{t})=1, \mathrm{t}>30
\end{array}
$$

Where $\bar{y} m=2.89 \quad$ with $t$-statistic $=-48.93$

$\Theta(1)=-.2436$ with t-statistic $=-2.15$

$\operatorname{Sm}(1)=.4071$ with t-statistic $=2.13$

$\mathrm{Um}(\mathrm{O})=.7508$ with $\mathrm{t}$-statistic $=3.08$

\section{DIAGNOSTICS.}

All parameter estimates are statistically significant at a .05 level with 75 degrees of freedom. Residual plots, autocorrelations, and partial autocorrelations of the residuals of Model 3 confirmed statistical adequacy except for spikes at lags 2 and 3. Subsequent modeling did not yield an acceptable alternative.

While significant spikes existed at low orders, the Ljung-Box Q statistic was insignificant for short and long lags equaling 18.49 at 24 degrees of freedom (Chi-Square $($ table $)=36.415$ for alpha $=.05$ for 24 df). The R-square of model (3) is

$$
R-s q u a r e(m)=1-\frac{\operatorname{MSE}(3)}{\operatorname{VAR}(\operatorname{Ym}(t))}=1-\frac{.1566}{.5314}=70.5 \%
$$

\section{INTERPRETATION.}

As with the other models, this model has good intuitive appeal. Prior to the intervention period, the mean skim milk selection rate was $2.89 \%$. Model (3) denotes that the impact of the game was gradual and permanent with an asymptotic change of $1.266 \%$.

Asymptotic change $(\mathrm{m})=\frac{\mathrm{Um}(\mathrm{O})}{1-\mathrm{S}(1)}=\frac{-.7508}{1-.4071}=1.266 \%$

This impact is a gradual and permanent effect, yielding a $44 \%$ increase in skim milk consumption. The effect is quite rapid, $93 \%$ of the asymptotic effect is achieved in only three days.

\section{Discussion}

The purpose of this report was to document the use of ARIMA-intervention methods in measuring the behavioral changes caused by a social marketing campaign, the "Food For Thought" game of the American Heart Association. Intervention methods were effective in measuring the form (simple, com- 
pound, gradual or abrupt), duration (temporary or permanent), and the intensity (the profile to the asymptotic limit) of the effects of the game. The results have confirmed the effectiveness of the nutritional messages and the manner in which they were presented at the UMKC cafeteria. The National Heart, Lung and Blood Institute changed eating habits in a National Institute of Health employee cafeteria through a "Food for Thought" game. In their study, an increase in purchases of skim milk and a decrease in purchases of bread and desserts, and in total calories consumed were found.' However, their research did not model the effects of the "Food for Thought" game using intervention time series procedures. Further details of this current research project are presented elsewhere."

The results of this study give rise to some considerations that might be explored in further research.

1. New food habits can be learned in the same way as old ones were - that is, by practice.

2. Alternative nutrition education approaches are needed to reach consumers who do not actively seek nutrition information.

3. It would be worth while to explore the impact of the "Food for Thought" nutrition education game in different settings such as hospitals', factories', and high school's cafeterias.

4. Similar, but less sophisticated, nutrition education games could be developed to meet the educational needs of children.

Finally, people can learn about nutrition if careful attention is paid to their needs and principles of effective communication. The methodology used here was invaluable in objectively and quantifiably measuring the intervention effects of nutrition media.

Appendix: Symbols and Conventions

\section{1) Acronyms}

\section{ARIMA: Autoregressive Integrated Moving Average}

2) Time Series Conventions

$Y_{t}:$ The $t^{\text {th }}$ observation of the time series

$\mathrm{Y}_{\mathrm{t}}$ : The $\mathrm{t}^{\text {th }}$ observation of a deviate time series.

$\mathrm{Y}_{\mathrm{t}}=\mathrm{Y}_{\mathrm{t}}-\theta_{\mathrm{o}} ; E \mathrm{Y}_{\mathrm{t}}=\mathrm{O}$

$a_{t}$ : The $t^{\text {th }}$ random shock of a white noise process.

$a_{t} \sim \operatorname{NID}\left(O, \sigma^{2}\right)$

B: The backward shift operator whose operation is

$$
\mathrm{B}^{\mathrm{nY}} \mathrm{Y}_{\mathrm{t}}=\mathrm{Y}_{\mathrm{t}}-\mathrm{n} ; \mathrm{B}^{\mathrm{n}} \mathrm{B}^{\mathrm{m}}=\mathrm{B}^{\mathrm{n}+\mathrm{m}}
$$

$\phi p:$ The $\mathrm{p}^{\text {th }}$ order autoregressive parameter.

$\Theta \mathrm{q}$ : The $\mathrm{q}^{\text {th }}$ order moving average parameter.

p: The order of autoregression (regular)

q: The order of moving average (regular).

S: The length of a seasonal cycle.

$\mathrm{N}^{t}$ : The noise component or stochastic process of the model.

$X_{(t)}$ : Represents the intervention components of the impact assessment model $\left(\mathrm{X}_{(\mathrm{t})}=\mathrm{O}\right.$ for $\mathrm{t}=1,30 ; \mathrm{X}_{(\mathrm{t})}$ $=1$ for $\mathrm{t}=31,80)$.

3) Mathematical Symbols

$$
\begin{array}{ll}
\imath: & \text { is distributed as } \\
=: & \text { equals }
\end{array}
$$

Asymptotic change $=\frac{\omega_{0}}{1-\hat{\delta}_{1}}$

Where $\omega_{0}$ represents omega - the $\mathrm{S}^{\text {th }}$ order input parameter of the transfer function.

$\delta$ represents delta - the $\gamma$ th order output parameter of the transfer function.

Asymptotic: In mathematical terms, means a line considered a limit to a curve in the sense tht the perpendicular distance from a moving point on the curve to the line approaches zero as the point moves an infinite distance from the origin.

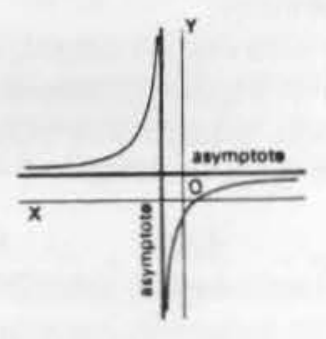

Change: $\begin{aligned} \hat{\omega}_{0}(1 & +\hat{\delta}_{1}+\hat{\delta}_{1}^{2}+\hat{\delta}_{1}^{3}+\hat{\delta}_{1}^{4} \\ & +\hat{\delta}_{1}^{5}+\ldots \ldots \ldots+\hat{\delta}_{1} 50\end{aligned}$

\section{References}

1. American Heart Association, Food For Thought Game. Dallas: American Heart National Center, 1980.

2. Zifferblatt S M, Wilbur C S, Pinsky J Changing Cafeteria Eating Habits. J Am Diet Assoc 1980; 76: $15-20$. 
3. Hussain S A: The Effectiveness of a Nutrition Education Game - Food for Thought - in Influencing the Food Selection Behavior of University Cafeteria Patrons. Presented at 17th Annual Convention of the Islamic Medical Association, St. Louis, MO, August 10-12, 1984.

4. Box G E P, Tiao G C: Intervention Analysis with Applications to Economic and Environmental Problems, J Am Statist Soc 1975; 70: 70-79.

5. Glass G V: Estimating the Effects of Intervention into Nonstationary Time Series. Am Educ Res J 1972; 9: 463-77.

6. Box G E P, Jenkins G M: Time-Series Analysis:
Forecasting and Control. San Francisco: HoldenDay, 1976.

7. BMDP Statistical Software. Berkley: University of California Press, 1983.

8. McCleary R, Hay R A, Jr: Applied Time Series Analysis for the Social Sciences. Beverly Hills: Sage Publictions, 1982.

9. Hussain S A: The Effects of Persuasive Communication and Cognitive Dissonance in Influencing the Food Selection Behavior of University Cafeteria Patrons. Unpublished dissertation. School of Education, University of MissouriKansas City, MO., 1983. 